\title{
Designing Rich Interactive Content for Blended Learning: A Case Study from Indonesia
}

\author{
Didik Dwi Prasetya ${ }^{1,2}$, Aji Prasetya Wibawa ${ }^{1}$, Tsukasa Hirashima² and Yusuke Hayashi ${ }^{2}$ \\ ${ }^{1}$ State University of Malang, Indonesia \\ ${ }^{2}$ Hiroshima University, Japan \\ didikdwi@um.ac.id \\ aji.prasetya.ft@um.ac.id \\ tsukasa@lel.hiroshima-u.ac.jp \\ hayashi@lel.hiroshima-u.ac.jp \\ DOI: 10.34190/EJEL.20.18.4.001
}

\begin{abstract}
Blended learning is a hybrid of traditional face-to-face and different types of online learning services. Blended learning offers synchronous and asynchronous learning experiences that combine the conveniences of online courses while maintaining in-person contact. Blended learning addresses the needs of students who are unable to attend classes entirely, but who nonetheless demand opportunities for personal interaction. The appropriate instructional content design becomes one of the crucial components to support the success of blended learning activities. This study proposed the development and practical use of document-based rich and interactive content in EPUB3 to provide an exciting instructional content model. EPUB3 is a digital publishing standard with prosperous features and flexible implementation that is widely accepted in academic and industry. The EPUB3 digital book content was integrated into a Moodle learning management system to support synchronous and asynchronous blended learning environments. A questionnaire was applied to find out the learners' responses and involved 155 undergraduate students at The State University of Malang, Indonesia. The questionnaire results showed the developed content model was feasible and suitable to be implemented in a blended learning environment. Students seem interested and enthusiastic about being involved in various learning activities that add new experiences.
\end{abstract}

Keywords: blended learning, instructional design, rich content, interactive, EPUB3

\section{Introduction}

E-learning is a process of expanding learning or delivering teaching materials to remote sites by utilizing computers and the Internet network. E-learning has been widely used in various fields and education levels, starting from preschool to higher education. E-learning offers a practical solution for solving essential problems in traditional or face-to-face learning. The issues are learning time limitation (Tsai, 2009) and the individual technology-based needs (Banditvilai, 2016). However, organizing pure online learning means leaving no problems at all. The electronic system offers little or no social interaction or dialogue (Sherman, 2000; Wan, Compeau, and Haggerty, 2012) with other learners and supervisors. This condition may lead to unreal collaboration and other worse social situations (Tayebinik and Puteh, 2012). Referring to the advantages and disadvantages of the two approaches, it would be more useful to combine e-learning and face-to-face learning to achieve all benefits. This combination technique is called blended or hybrid learning.

The blended learning approach is considered as an answer that offers practical solutions to facilitate learning processes that cannot be exclusively done in the classroom, either because of work, location, or undesirable circumstances such as disasters and an outbreak of diseases. Blended learning design is suitable for busy students who can still attend the class. The blended learning approach can help older or working students to keep the balance between school, family, and work activities without harming any of them (Lungu, 2013). It may effectively improve the teaching and learning experience for both instructors and students (Shih, 2010). Blended learning education has been widely implemented in universities due to its benefit for providing timely, continuous, and flexible learning (Prasad et al., 2018). However, if viewed from the perspective of infrastructure, higher education is the readiest academic level to apply information technology comprehensively. Mirriahi, Alonzo, and Fox (2015) argued that blended learning had been widely employed, particularly in higher education contexts. Thus, the suitability of this condition will support the implementation of blended learning optimally and in accordance with expectations.

Instructional content design is one essential element that supports the success of blended learning approach. Instructional design helps to determine the strategies that will lead to accomplishing the goals established based on needs analysis (Lim, 2002). In e-learning systems, students feel a sense of emotional and physical distance 
from their learning environments (Lee and Rha, 2009). Effective instructional design can address this distance and potentially compensate for it to allow learners to maintain focus and motivation and to support them as they navigate their learning path (Costley, Hughes, and Lange, 2017). The instructional design considers the ways "the instructors, learners, content materials, instructional activities, delivery systems, and learning and performance environments interact and work with each other to bring about desired student learning outcomes" (Dick, Carey, and Carey, 2015). In reality, in technology-based learning, attention is often focused on technology implementation, while the proper content design is less considered (Hofmann, 2011).

Blended learning represents a switch from passive learning to active learning and adds a human touch to facilitate interactive content (Kaur, 2013). One potential document format that offers dynamic and interactive content is EPUB (Prasetya and Hirashima, 2018). EPUB is an open and industry-standard format for eBooks maintained by the International Digital Publishing Forum (IDPF) and may be used across different hardware devices (Garrish, 2011; Williams, 2011; Prasetya and Hirashima, 2018). EPUB has been widely used, and it works well in the academic journal since 2007, with the release of version 2.0 (Eikebrok, Dahl, and Kessel, 2014). Compared to the old and widely used PDF format, EPUB3 is richer, reflowable content, interactive, and it is accessible through a variety of desktop and mobile devices (Prasetya, Wibawa, and Hirashima, 2018). Reflowable content allows the e-book can be opened through a variety of reader application device with a fit and comfort view. The interactive content enables the instructor to create a high level of interest, accountability, and real assessment (Kaur, 2013). EPUB3 has features to support synchronous and asynchronous learning implementation.

This study proposed a rich and interactive content model to realize appropriate instructional design in blended learning. Caladine (2008) argued that enhancing electronic learning with media-rich content and interaction can increase its efficiency and effectiveness. Rich media presents multimedia-based content that is easily distributed to provide a unique and more precious consumer experience. This study focused on the use of EPUB3 documents to deliver learning content that is consistent with the characteristics of blended learning. The EPUB3 digital book content was integrated into the Moodle learning management system platform with case studies at the State University of Malang, East Java, Indonesia. This study involved a questionnaire in collecting data about student perceptions about the EPUB3 content model.

\section{Literature Review}

\subsection{Blended Learning}

There are many formal definitions of blended learning, but most of them are around the face-to-face and online environment. Many researchers agree that the concept of blended learning is derived from two terms, blend and learning. The term blend refers to combining things, and learning denotes the assimilation of new knowledge (Olivier, 2011). Blended learning can be defined as a mixture of face-to-face teaching, characterized by synchronous and human interaction, and full e-learning, which are asynchronous (Graham, 2006; Chaeruman, Wibawa, and Syahrial, 2018). Cronje (2020) argues that in a modern perspective, blended learning should not merely around the blend of online and face-to-face instruction but also involve the learning theory. There are three essential components of blended learning: (1) learning environment; (2) instruction; and (3) media (Kaur, 2013).

Blended learning describes learning activities that involve a systematic combination of co-present (face-to-face) interactions and technologically-mediated interactions between students, teachers, and learning resources (Bliuc, Goodyear, and Ellis, 2007). Garrison and Vaughan (2008) define blended learning as "the thoughtful fusion of face-to-face and online learning experiences," emphasizing the need for reflection on traditional approaches and for redesigning learning and teaching in this new terrain. In this paper, blended learning is defined as a deliberate combination of the self-directed study of offline content deployed on tablets, with occasional faceto-face meetings, moderated through instructor-led sessions (Onguko, 2014). A learning delivery approach that blends face-to-face classroom learning and online learning, blended learning provides such flexibility as anytime and anywhere access to learning management systems (Tang and Chaw, 2016). Blended learning, that is, "a course that uses a combination of face-to-face and online learning," provides a middle ground to explore. Yet, mixed models come in different forms, shapes, and sizes (Akbaba and Başkan, 2017).

Blending approach provides various benefits overusing any single learning delivery type alone: Improved Learning Effectiveness, Extending the Reach, Optimizing Business Results, and Optimizing Development Cost and 
Time (Singh and Reed, 2001). There are several potential advantages to blended learning that are emerging. Some of these revolve around accessibility, pedagogical effectiveness, and course interaction (Dziuban, Moskal, and Hartman, 2005). Busy students like the ability to access course materials anytime, anyplace, and they are positive about the convenience and flexibility these blended courses provide them. Moreover, many students are older and working, such as the adult students in the life-long learning education system, and blended courses help provide them with the flexibility they need to balance school, family life, and work (Lungu, 2013). According to Shih (2010), blended learning that integrates online and face-to-face instruction could create an effective teaching and learning experience for both instructors and students. Poon (2013) stated that enhancing students' motivation to learn on their own "at their own pace and in their own time" is a critical aspect of a blended learning environment.

Many blended learning studies have been conducted and have produced various findings. Liu (2016) investigated whether blending a class video blog into face-to-face instruction may simultaneously enhance university students' actual learning performance and effective outcome. The findings suggested that incorporating a class video blog into face-to-face instruction is beneficial for strengthening the overall oral test performance significantly. Tsai (2017) conducted an applied study on developing a lesson plan for a Java Programming course at a higher education level. Tsai utilized EPUB document version 3.0 (also called EPUB3) for delivering curricular content. Tsai's lesson plan design accommodates textual content, hyperlinks, and interactive test features. Through the questionnaire for the e-book-based EPUB3 functions, it stated that the proposed approach was advantageous and useful. Prasad et al. (2018) conducted a blended learning experiment designed for postgraduate international IT students. The research used a unified theory of acceptance and use of technology (UTAUT) framework to evaluate user behavior during the adoption of a blended learning model into an IT Project management subject. The investigation results indicated that there were significant relationships and dependencies between perceived ease of use, perceived usefulness, attitude towards usage and impact on students' behavioral intention to use the blended learning model in their studies. The study also highlighted that students had significant internal motivation to engage with unfamiliar technology. Tsai (2017) studied the effects of using an EPUB3 eBook-based flip blended learning model in the academic course environment. The results indicated that EPUB3 could enhance the flip model with more flexible and attractive features.

\subsection{Blended Learning Setting}

According to Smaldino et al. (2008), learning settings are defined as situations and conditions in which a learning event can occur. Learning settings in this study consist of two main categories, namely, asynchronous learning and synchronous learning (Hrastinski, 2008). Asynchronous e-learning, commonly facilitated by media such as email and discussion boards, supports work relationships between learners and with teachers, even when participants cannot be online at the same time. This type of learning represents flexible e-learning; it is possible for learners to log on to an e-learning environment at any time. On the other side, synchronous e-learning, commonly supported by media such as video conferencing and chat, has the potential to help e-learners in the development of learning communities. Learners and teachers experience synchronous e-learning as more social and avoid frustrations by asking and answering questions in real-time. With these kinds of systems, instructional delivery, and communication between instructors and students can be performed at the same time (synchronously) or at different times (asynchronously) (Wu, Tennyson, and Hsia, 2010).

Referring to the Chaeruman, Wibawa, and Syahrial (2018), a model of blended learning setting can be divided into four quadrants as follows:

1. Live Synchronous (LS) is the learning between student and teacher that occurs at the same time and place (face-to-face). Learning activities that happen include lectures, discussions, presentations, workshops, lab practice, mentoring, role modeling, and field study.

2. Virtual Synchronous (VS) is the learning between students and teachers that happen at the same time, but different places from one and another. Learning activities in this quadrant include ementoring, audio conferencing, video conferencing, and web-based seminars (webinars).

3. Self-directed Asynchronous (SA) is a learning experience that occurs between the learner and the learning resources at any time or place under their own pace and control. This learning approach can be facilitated by various media contents, such as simulations, animations, scenarios, workbooks, online resource links, and online self-assessments.

4. Collaborative Asynchronous (CA) is a learning experience that transpires between the learner and the learning resources at any time or place with other resource persons. Learning activities in this 
approach can be mediated by asynchronous learning tools such as email, online bulletin boards, discussion forums, mailing lists, and online assignments.

\section{Methods}

\subsection{Research Design}

The development of the digital-book software application was done by referring to the waterfall process model (Pressman, 2015). The main reason for using this model is due to the highly suitable product characteristics, in which the specifications of this product development have been well identified, including the necessary supporting technologies. Pressman has revised this model into five main stages, starting from communication, planning, modeling, construction, and deployment. The communication stage consists of two activities: project initiation and requirements gathering. The planning stage focused on product planning activities, including estimating, scheduling, and tracking. In the modeling phase, there are two main activities involved: analysis and design. Construction is the stage to realize the results of the investigation to the program code. The primary purpose of the deployment phase is to deliver the product to the end-user.

The phases of the waterfall model of software development are carried out systematically and sequentially. Each stage in this model is related; the next stage requires the previous stages as input until all the stages are completed. This characteristic will produce a product that has a higher cohesion because everything in each phase is well understood. The study included practical use involving several participants to complete the product development phase. The subjects in this study were 5 class (offering) of the second year undergraduate Education of Informatics Engineering majors at the Faculty of Engineering, State University of Malang, Indonesia. The total number of participants was 155 students, with details of each class A (32 students), B (31 students), C (29 students), D (32 students), and E (31 students).

\subsection{Learning Content Model}

The term model used in this study refers to the proposed rich and interactive content as an approach to provide an appropriate instructional design. This content model was developed using the EPUB3 document format. EPUB3 has excellent potential as a standard for future digital books and is widely used in the academic and publishing industry. EPUB offers a public and open structure that makes it easy to be created, modified, and integrated into other documents (Prasetya, Wibawa, Hirashima, 2018).

The present study attempted to provide a content model that can be integrated into the Moodle LMS system. The content model was packaged in the digital book form, which has the following main structure:

1. Basic Materials

The Basic Materials section provides necessary materials for Web Programming courses for undergraduate students of Education of Informatics Engineering. The material structure is adapted to the applicable curriculum. The content form of this material is the same as the printed book, but with the addition of video content to provide a clearer visual picture.

2. Interactive Live Editor

This section is a facility to practice the practical concepts of HTML web programming. An interactive live editor is an exciting feature that simplifies the HTML encoding stage through a single window.

3. Interactive Quiz

Interactive quiz content was provided to evaluate the students' performance on the web programming topic. Although the available question banks are fixed, because it is integrated into the EPUB document, the presentation of the problem is done randomly.

The development phase of the EPUB3 digital book application was done by using the Sigil application (https://sigil-ebook.com/). Sigil is a free, open-source, multi-platform EPUB e-book editor that is very simple and easy to use. Some additional settings regarding CSS (Cascading Style Sheets) and scripting were also done to customize the design and functionality of digital books. To test the digital book view on a desktop PC or laptop, we use the Readium EPUB reader (http://readium.org/) and Azardi e-book reader (http://azardi.infogridpacific.com/). While on mobile platforms (smartphone and tablet PC), we use GitdenReader (http://gitden.com). After the product development phase was completed, an internal evaluation was performed to ensure product functionality. The internal review was conducted by the software developer using the black-box method. Each module that represents the primary functions was run, and the results were observed. 
This study highlighted the appropriate combination of synchronous and asynchronous approaches to create a learning experience and meeting learning outcomes. The lectures at the State University of Malang in one semester consist of 16 meetings (including a midterm, excluding final exam). Web Programming course conducted during the first semester of the academic year 2017/2018 has 4 hours presentation time (4x50 minutes). This course has 11 learning outcomes. As an illustration, the first learning outcome was mapped into the blended learning setting, as in Table 1.

Table 1: Blended learning setting (first learning outcome)

\begin{tabular}{|c|c|c|c|c|c|c|c|}
\hline Course Name & \multicolumn{7}{|l|}{ Web Programming } \\
\hline \multirow{3}{*}{$\begin{array}{l}\text { Learning } \\
\text { outcomes }\end{array}$} & \multirow{3}{*}{ Subjects } & \multirow{3}{*}{ Subject units } & \multicolumn{4}{|c|}{ Learning settings } & \multirow{3}{*}{ Descriptions } \\
\hline & & & Asy & onous & Syn & onous & \\
\hline & & & SA & $\mathrm{CA}$ & LS & VS & \\
\hline \multirow{4}{*}{$\begin{array}{l}\text { Students } \\
\text { understand the } \\
\text { basic concepts of } \\
\text { HTML to create } \\
\text { web application } \\
\text { documents. }\end{array}$} & $\begin{array}{l}\text { Introduction to } \\
\text { Internet and web }\end{array}$ & $\begin{array}{l}\text { Introduction to } \\
\text { Internet and web } \\
\text { Web technologies } \\
\text { Web components }\end{array}$ & & & $\checkmark$ & & $\begin{array}{l}\text { \#Week } 1 \\
\text { Presentation } \\
\text { and discuss } \\
\text { (50 minutes) }\end{array}$ \\
\hline & Basic HTML & $\begin{array}{l}\text { Introduction to HTML } \\
\text { HTML specifications } \\
\text { HTML structures } \\
\text { HTML documents } \\
\text { Web server } \\
\text { preparation }\end{array}$ & $\checkmark$ & & $\checkmark$ & & $\begin{array}{l}\text { \#Week } 1 \\
\text { Presentation } \\
\text { and discuss } \\
\text { (150 minutes) } \\
\text { Practice } \\
\text { (EPUB3) } \\
\text { Individual task }\end{array}$ \\
\hline & HTML Form & $\begin{array}{l}\text { HTML components } \\
\text { Basic form } \\
\text { Web form } \\
\text { Advanced } \\
\text { components }\end{array}$ & $\checkmark$ & & & & $\begin{array}{l}\text { \#Week } 2 \\
\text { Online study } \\
\text { Practice } \\
\text { (EPUB3) } \\
\text { (200 minutes) }\end{array}$ \\
\hline & HTML 5 Validation & $\begin{array}{l}\text { HTML } 5 \text { features } \\
\text { Form validation } \\
\text { Advanced validation } \\
\text { (using regular } \\
\text { expression) }\end{array}$ & & $\checkmark$ & & $\checkmark$ & $\begin{array}{l}\text { \#Week } 3 \\
\text { Virtual class } \\
\text { Group task } \\
\text { (analyze } \\
\text { advanced } \\
\text { validation } \\
\text { pattern) } \\
\text { (200 minutes) }\end{array}$ \\
\hline
\end{tabular}

In the blended learning setting in Table 1, the realization of the learning strategy was considered appropriate, which involved synchronous and asynchronous activities. For example, the first learning outcome consisting of 4 subjects, teachers and students met only once in the class. This initial meeting is considered necessary because the teachers need to explain the description of lectures, materials, activities map, types of assignments, assessment components, references, and related rules. Furthermore, at the second meeting, students were directly involved in self-asynchronous strategies for self-learning online and hands-on practice using EPUB3 digital books. In the third week, the teacher invited students to implement a virtual synchronous strategy through a virtual classroom and continued with group work in collaborative asynchronous.

\subsection{Measurement}

This study involved three types of measurement: evaluation of learning media, evaluation of learning content, and practical use on university students. An expert-designed questionnaire with 4-point scales of a Likert Scale (from 1 = poor to 4 = very good) was used in all evaluations. The reliability of the students' questionnaire was examined using Cronbach's alpha.

The questionnaire of learning media focused on aspects of software engineering ( 9 statements), learning design (6 statements), and visual communication ( 9 statements), with a total of 24 statements. This evaluation was conducted by two media experts, both of whom were senior lecturers at the State University of Malang. The first reviewer is a lecturer from the Department of Learning Technology who has 23 years of teaching experience, while the second reviewer is a lecturer from the Department of Electrical Engineering who has taught for 21 years. The average result of the level of agreement from the learning media review was $94.27 \%$, with a standard deviation of 0.35 .

Evaluation of learning content involved learning design (19 statements) and visual communication 3 statements) aspects, with a total, of 22 statements. Two experienced lecturers conducted this evaluation at the State 
University of Malang with the background of Informatics Engineering and Education of Informatic Engineering, respectively. These two reviewers were considered relevant to this experimental material because both have taught web programming courses. Reviewers of content evaluation gave the average percentage of validity scores of $88.64 \%$, with a standard deviation of 0.47 .

Practical use on university students was intended to investigate the feasibility of the product from the user's side. In this activity, participants were given EPUB3 document-based learning content, and they carry out learning according to the setting. At the end of the lesson, students were given a questionnaire to respond to the material design has been used. There were three aspects involved in the assessment instruments for students, including software engineering (4 statements), learning design (12 statements), and visual communication (4 statements), with a total of 20 statements. Software engineering aspects include digital book compatibility, ease of operation, live editor module functionality, and screen display responsiveness. Learning design aspects confirm the availability of learning designs in digital books, such as learning objectives, evaluations, case studies, the role of live editors, and practice quizzes. The final aspect includes the suitability of language, text and illustrations, the choice of font type and size, and the ease of navigation between pages.

\section{Results}

This study utilized a Moodle platform to implement the blended learning environment in the higher education level. As explained in the design of the learning setting, this blended learning implemented synchronous and asynchronous approach. The existence of a Moodle system is essential to support virtual synchronous, selfpaced, asynchronous, and collaborative asynchronous learning activities. It should be highlighted that the focus of this research is the development of interactive EPUB3 content that will be integrated into the Moodle application. After successfully creating the digital book, the next step is to integrate the book into Moodle to be accessible to students. The EPUB3 content was incorporated into the Moodle system by lecturers as well as inserting other documents such as PDF format. An example of the results of the EPUB3 integration content is shown in Figure 1.

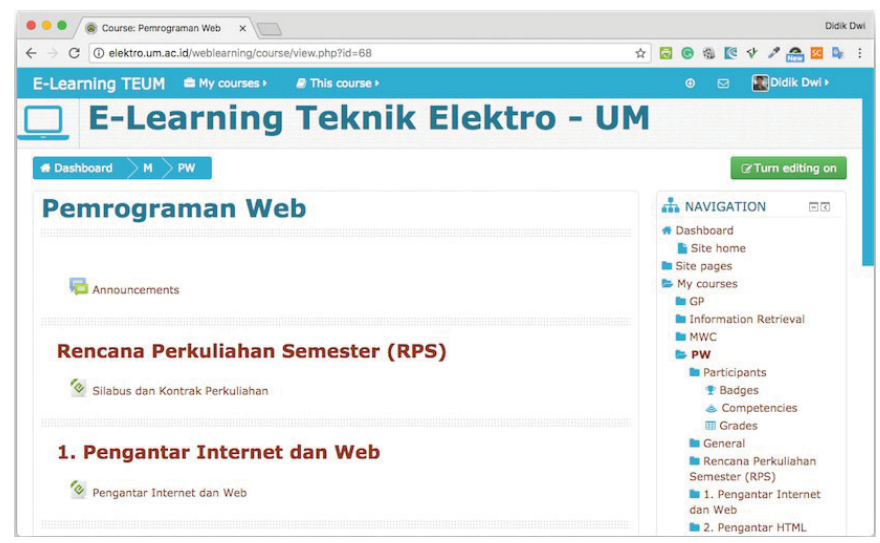

Figure 1: Integration of EPUB3 contents into the Moodle platform

The main purpose of this development research is to produce a rich learning content for use in blended learning environments. Rich content is a term used to describe various types of materials. The existence of varied content is fascinating to implement in the learning environment. The selection of EPUB3 documents format is suitable for realizing rich and interactive learning content.

One of the features of digital books that represent content variations is the use of multimedia content. Therefore, EPUB3 document content is designed to be exciting and utilizes multimedia elements such as text, pictures, audio, animation, and video. Many researchers have concluded that the implementation of multimedia content in learning can increase the student's motivation. The teaching approach with the utilization of multimedia learning can be more effective ( $\mathrm{Ni}, 2017)$. One of the video screens that explain the installation phase needs and the programming tutorial is shown in Figure 2. 


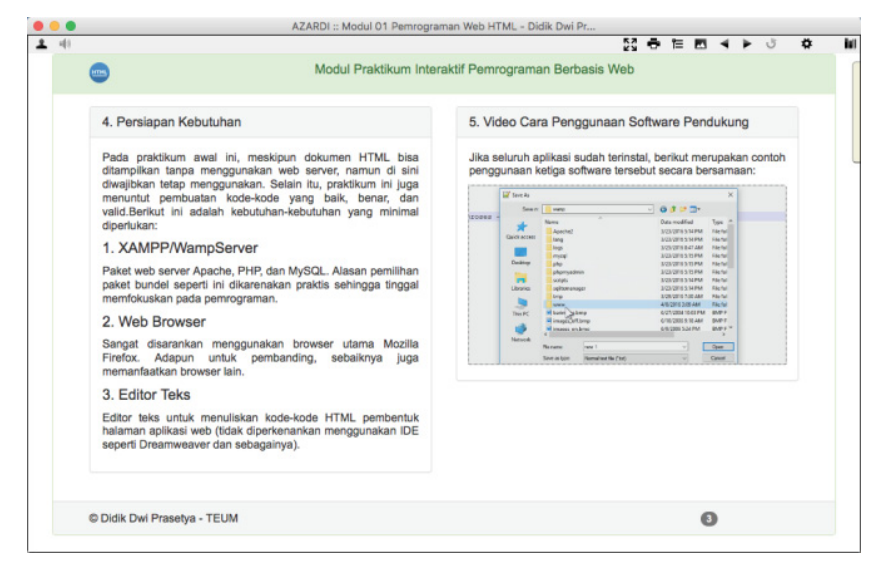

Figure 2: Video content of EPUB3 digital book

The digital book structure is adjusted to that of a general printed book design. The first page is the cover page, then the copyright page, introduction page, table of contents page, chapters, and references. The purpose of the layout structure is intended to facilitate the use of the product quickly, even for beginners. As a textbook for general learning, the digital book contains necessary materials for web programming materials and related exercises. Students can use desktop and mobile reader applications to read the book.

The main advantage of this digital book is an interactive content realized through the HTML text editor. This feature allows students to type in HTML code and view the result immediately without having to open the browser in another window. This approach enables students to focus on a single page of digital books, making it easier to create program code. This text editor also facilitates line numbers and highlighting tags in the text area to ease student coding activities. The HTML code view on the interactive text editor page is shown in Figure 3.

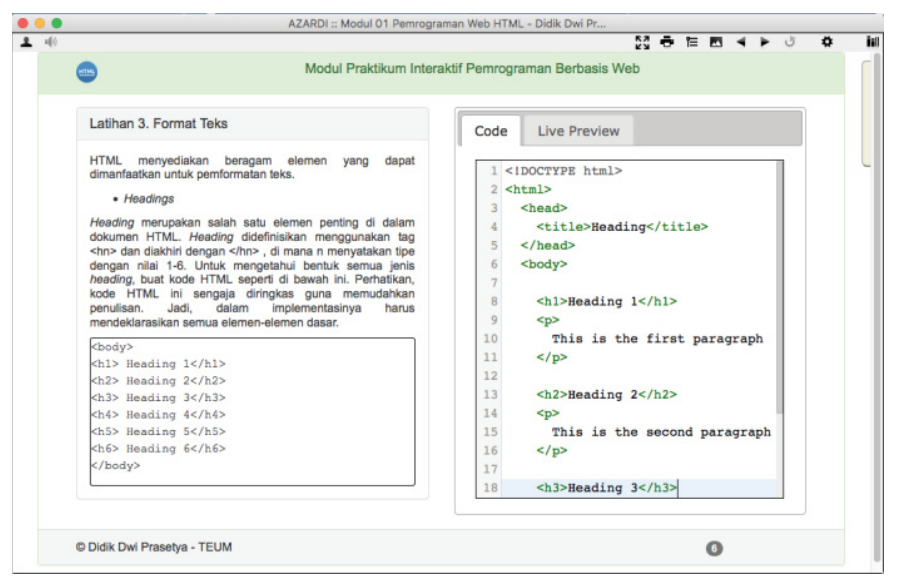

Figure 3: Live editor to support HTML code practice

The live editor feature was developed using HTML5, CSS, and scripting. This text editor work is the same as web browsers, which has encoded HTML tags into the results view. An example of a result view from an HTML editor can be seen in the Live Preview tab, as shown in Figure 4.

In this study, the ability of live editor is still limited to the codes to build static webs, such as HTML, CSS, and JavaScript. Therefore, students cannot yet use server-side codes, such as PHP. However, this feature is beneficial for students, especially when they have mobile activities and implement blended learning.

This digital book also provides content evaluation pages to complete a variety of content. This content contains material evaluations per chapter that can be used as a preliminary evaluation. This evaluation content is not intended to replace a more complex assessment provide by Moodle. However, the evaluation content in digital books has limitations because it does not support dynamic programming, so the presentation of the question is in a fixed or static manner. The evaluation of multiple-choice questions is shown in Figure 5. 


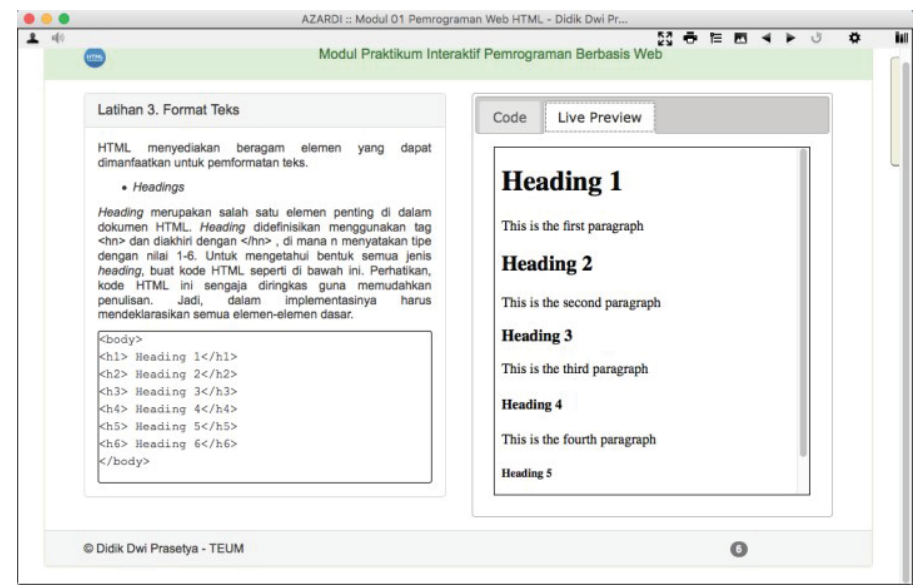

Figure 4: Preview of live editor

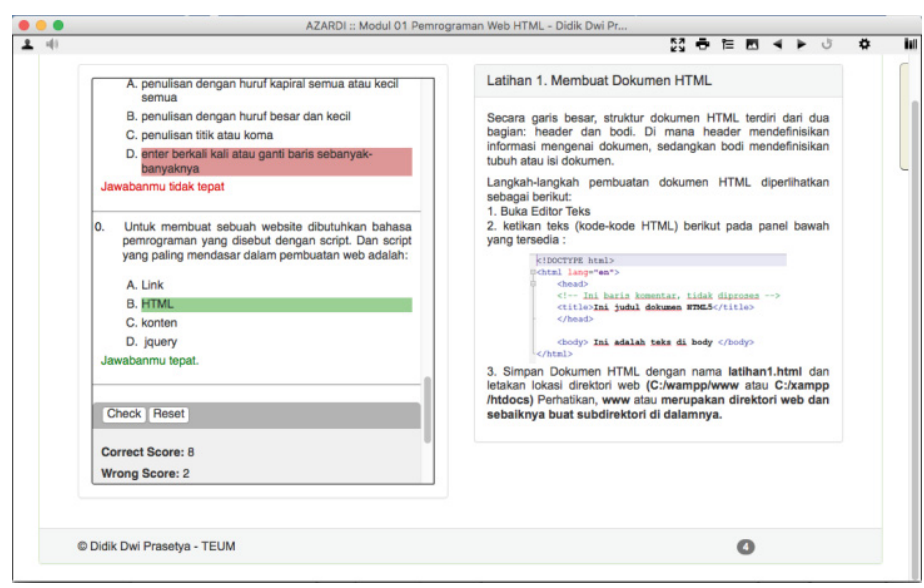

Figure 5: Evaluation content

In this evaluation content, students can answer the available questions and then press check to get feedback from the digital book. This multiple-choice evaluation feature was developed using embedded scripting in a digital book and not connected to the source of a question. As for preventing students from just memorizing the correct answer position, this multiple choice can be adjusted to display random answer choices. Another feature provided by the digital book is a reflowable layout, following the EPUB 3.0 specifications. In contrast to the fixed layout (for example, PDF), reflowable content is accessible easily through a variety of desktop/laptop and mobile devices readers. This feature is essential and attractive because it can provide the best display for each screen reader and is relevant to the characteristics of blended learning.

After the development of the digital-book was completed, the next step is to conduct practical use and review the product. The practical use was done at a higher education level and applied the synchronous and asynchronous model. The classroom situation when implementing live synchronous learning (face-to-face) is shown in Figure 6.

According to the design of blended learning settings, this digital book is also applied to support asynchronous learning. Figure 7 shows the classroom situation when implementing collaborative asynchronous learning using the interactive digital book.

Practical use on university students was intended to investigate the feasibility of the product from the user's side. In this activity, participants were given EPUB3 document-based learning content, and they carry out learning according to the setting. In connection with blended learning settings, practical use was carried out during three lectures. Questionnaires were given to students on the third meeting or the end of experimental use.

Descriptive statistics on aspects of software engineering, learning design, and visual communication of questionnaire results are shown in Table 2. Cronbach's alpha on the aspect of software engineering was 0.7 , 
indicated acceptable internal consistency. Furthermore, an achievement of the learning design aspect showed good internal consistency with Cronbach's alpha was 0.84 . Cronbach's alpha in the visual communication aspect also stated good internal consistency with a value of 0.81 .

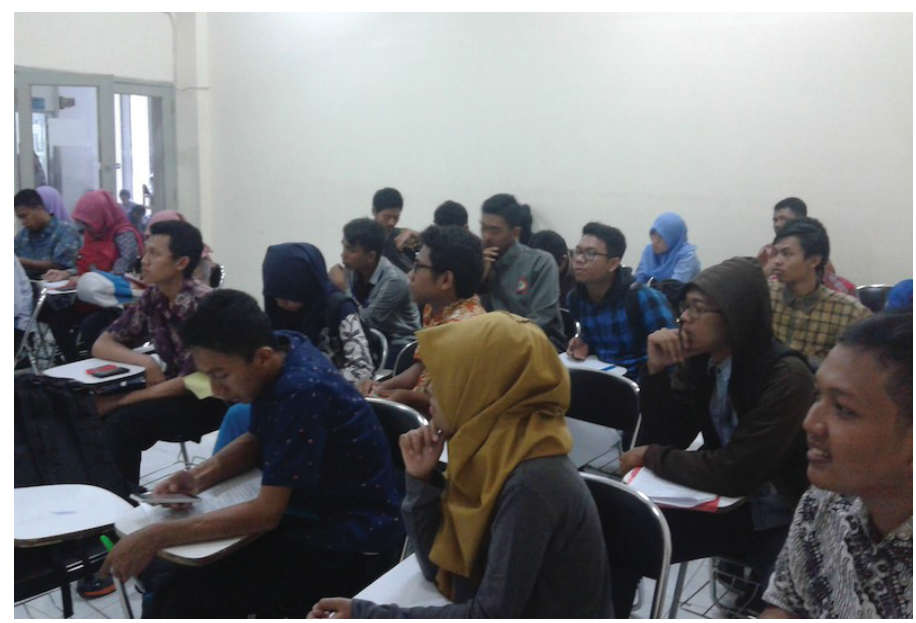

Figure 6: Live synchronous learning in the classroom

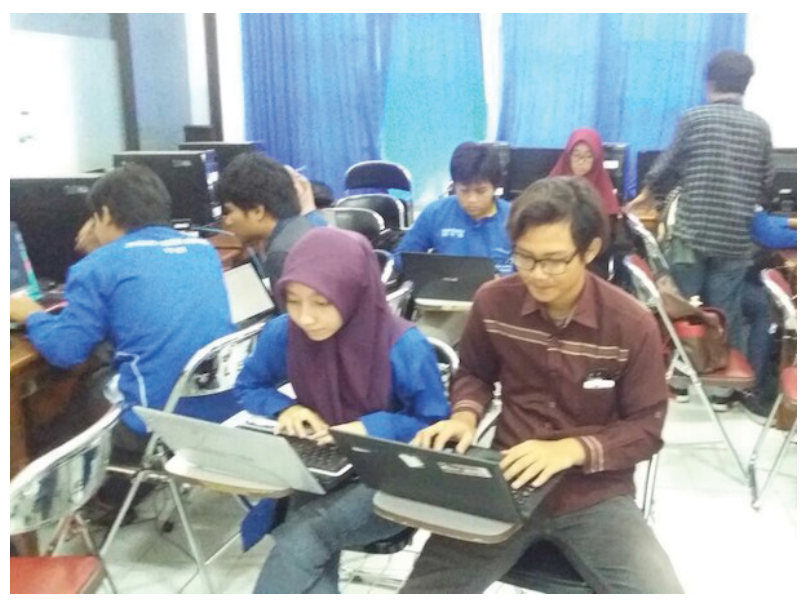

Figure 7: Collaborative asynchronous using interactive digital book

Students' questionnaire results showed the mean of software engineering, learning design, and visual communication aspects was 3.5. This value was between a scale of 3 (good) and 4 (very good). Thus, it appears that participants stated that EPUB3 digital book content was appropriate for use in the blended learning approach.

Table 2: Descriptive statistics of questionnaire aspects

\begin{tabular}{|l|l|l|l|l|l|}
\hline No & Aspects & Number of Items & Mean & Std. Deviation & Cronbach's Alpha \\
\hline 1 & Software engineering & 4 & 3.6 & 0.49 & 0.70 \\
\hline 2 & Learning design & 12 & 3.5 & 0.56 & 0.84 \\
\hline 3 & Visual communication & 4 & 3.4 & 0.56 & 0.81 \\
\hline
\end{tabular}

\section{Discussion}

The present study suggested a rich and interactive content model that is appropriate to be implemented in a blended learning environment. Rich and interactive content models were realized using EPUB3 documents that support various types of digital content, such as text, images, sound, video, animation, and interactive content. EPUB3 content is also accessible using desktop/laptop or mobile electronic devices (tablet PCs, e-book readers, and smartphones). Based on the characteristics and features available, EPUB3 is seen as one of the potential future book formats (Eikebrokk, Dahl, and Kessel, 2014). The EPUB3 features are appropriate for realizing synchronous and asynchronous situations in blended learning. 
Interactive content is another essential feature needed to provide an exciting and challenging learning environment for learners. The functionality was realized in a digital book through an interactive HTML live editor and multiple-choice quizzes. The interactive HTML editor is useful for students to practice the studied web programming material directly in an appeal and natural way. Meanwhile, the existence of an interactive quiz is necessary as a method to evaluate students' knowledge. Interactive features can provide automatic feedback that can be used to measure students' abilities appropriately and independently without involving the teacher's role.

EPUB3 media evaluation results showed that the format of this document has the potential to provide featurerich documents. Content review consistently also states the suitability of EPUB3 in delivering content in a blended learning environment. Students' questionnaire results emphasized that EPUB3 is suitable for use in a variety of learning settings. This document format is not only able to present rich content, but also offers new experiences in learning. The current findings emphasized that EPUB3 rich content is ready to answer the challenges of blended learning related to instructional design.

\section{Conclusion}

An appropriate instructional content design has a crucial role in supporting the fruitfulness of blended learning. The present study proposed a rich and interactive learning content model based on the EPUB3 document format. EPUB3 is a future format standard that supports multimedia and interactive content. EPUB3 features are well suited to be used in supporting synchronous and asynchronous activities in a blended learning environment. The application of digital books based on EPUB3 is one of the right strategies to realize appropriate instructional design in blended learning. The integration of EPUB3 into the Moodle system can optimize and achieve an active blended learning environment.

The main contribution of the current study was to propose a rich and interactive EPUB3 document as an appropriate instructional design content in a blended learning environment. To measure the validity of the use of this content model, product evaluation and experimental use were involved. The results of media and content evaluations of EPUB3 digital books showed that this e-book format is appropriate for use in learning. Students also stated that the EPUB3 approach offers interesting and suitable content to be used in a blended learning environment. Overall, participants expressed a high level of satisfaction with the use of EPUB3 digital books. Rich and interactive content is proven to be able to present new experiences for students of the State University of Malang.

Although this study found that EPUB3 documents are suitable for use in blended learning, an investigation is needed to uncover their effects on students' learning outcomes. Future works should involve the control group to observe the performance of a rich and interactive learning content model. Further experimental use should also consider the more significant participants to examine the effects extensively. In addition, EPUB3 digital books should utilize online features to record students' achievements.

\section{Acknowledgments}

Thanks to the Islamic Development Bank (IsDB) for Ph.D. scholarship in partnership with Universitas Negeri Malang (UM), Indonesia. Also, huge thanks to Hirashima-sensei in Dept. of Information Engineering, Hiroshima University, Japan. Thank you also to M. Angga Gumilang for helping with this study.

\section{References}

Akbaba, Y. and Başkan, F., 2017. How to merge courses via Skype ${ }^{\mathrm{TM}}$ ? Lessons from an international blended learning project. Research in Learning Technology, 25, pp. 1-18.

Banditvilai, C., 2016. Enhancing students' language skills through blended learning. Electronic Journal of e-Learning, 14(3), pp.220-229.

Bliuc, A.M., Goodyear, P. and Ellis, R.A., 2007. Research focus and methodological choices in studies into students' experiences of blended learning in higher education. The Internet and Higher Education, 10(4), pp.231-244.

Caladine, R. (Ed.). 2008. Enhancing e-learning with media-rich content and interactions. Hershey, PA: Information Science Publishing.

Chaeruman, U.A., Wibawa, B., and Syahrial, Z., 2018. Determining the appropriate blend of blended learning: a formative research in the context of Spada-Indonesia. American Journal of Educational Research, 6(3), pp.188-195. 
Costley, J., Hughes, C., and Lange, C., 2017. The effects of instructional design on student engagement with video lectures at cyber universities. Journal of Information Technology Education, 16(1), pp. 189-207.

Cronje, J. C. 2020. Towards a New Definition of Blended Learning. Electronic Journal of e-Learning, 18(2), pp. 114-121.

Dick, W., Carey, L., and Carey, J. O., 2015. The systematic design of instruction. New York: Pearson

Dziuban, C., Moskal, P., and Hartman, J., 2005. Higher education, blended learning, and the generations: Knowledge is power: No more. Elements of quality online education: Engaging communities. Needham, MA: Sloan Center for Online Education.

Eikebrokk, T., Dahl, T.A., and Kessel, S. 2014. EPUB as publication format in open access journals: tools and workflow. Code4Lib Journal. [online] Available at: http://journal.code4lib.org/articles/9462 [Accessed 3rd April 2020].

Garrish, M. 2011. What is EPUB 3?. CA: O'Reilly Media.

Garrison, D.R. and Vaughan, N.D., 2008. Blended learning in higher education: framework, principles, and guidelines. San Francisco: Jossey-Bass.

Graham, C., 2006. Blended learning systems, definitions, current trends and future directions. The handbook of blended learning: global perspectives, local designs. San Francisco: John Wiley and Sons.

Hofmann, J., 2011. Top 10 challenges of blended learning. Training, 48(2), pp.12-13.

Hrastinski, S., 2008. Asynchronous and synchronous e-learning. Educause Quarterly, 31(4), pp.51-55.

Kaur, M., 2013. Blended learning-its challenges and future. Procedia-Social and Behavioral Sciences, 93, pp.612-617.

Lee, H. J., and Rha, I. 2009. Influence of structure and interaction on student achievement and satisfaction in Web-based distance learning. Educational Technology and Society, 12(4), pp. 372-382

Lim, C.P., 2002. Trends in online learning and their implications for schools. Educational Technology, 42(6), pp. 43-54

Liu, M.H., 2016. Blending a class video blog to optimize student learning outcomes in higher education. The Internet and Higher Education, 30, pp.44-53.

Lungu, I., 2013. The increasing need for blended-learning models in courses of English for specific courses in Romanian Universities: Procedia-Social and Behavioral Sciences, 76, pp.470-475.

Mirriahi, N., Alonzo, D., and Fox, B., 2015. A blended learning framework for curriculum design and professional development. Research in Learning Technology, 23(1), p.28451.

$\mathrm{Ni}, \mathrm{D} ., 2017$. Design and research on English Listening Teaching assisted by computer multimedia. International Journal of Emerging Technologies in Learning (iJET), 12(01), pp.32-43.

Olivier, J., 2011. Accommodating and promoting multilingualism through blended learning, (Doctoral dissertation). NorthWest University, Vanderbijlpark, South Africa.

Onguko, B.B., 2014. JiFUNzeni: A Blended Learning Approach for Sustainable Teachers' Professional Development. Electronic Journal of E-Learning, 12(1), pp.77-88.

Poon, J., 2013. Blended learning: an institutional approach for enhancing students' learning experiences. Journal of Online Learning and Teaching, 9(2), p.271.

Prasad, P.W.C., Maag, A., Redestowicz, M., and Hoe, L.S., 2018. Unfamiliar technology: reaction of international students to blended learning. Computers and Education, 122, pp.92-103.

Prasetya, D. D. and Hirashima, T., 2018. Design of multimedia-based digital storybooks for preschool education. International Journal of Emerging Technologies in Learning (iJET), 13(02), pp. 211-225.

Prasetya, D.D., Wibawa, A.P. and Hirashima, T., 2018. An interactive digital book for engineering education students. WTE and TE journal 16, (1), pp. 54-59).

Pressman, R. S., 2015. Software engineering: a practitioner's approach. Eighth Edition. New York, McGraw-Hill.

Sherman, L. W., 2000. Cooperative learning and computer-supported intentional learning experiences. Cyber Psychology and Behavior, Special Issue, 3(1), pp. 113-130.

Shih, R.C., 2010. Blended learning using video-based blogs: Public speaking for English as a second language students. Australasian Journal of Educational Technology, 26(6), pp. 883-897.

Singh, H. and Reed, C., 2001. A white paper: achieving success with blended learning. Centra Software, 1, pp.1-11.

Smaldino, S.E., Lowther, D.L., Russell, J.D., and Mims, C., 2008. Instructional technology and media for learning (8th ed.). Upper Saddle River, NJ: Pearson Education.

Tang, C. M. and Chaw, L. Y., 2016. Digital literacy: a prerequisite for effective learning in a blended learning environment? Electronic Journal of e-Learning, 14(1), pp. 54-65.

Tayebinik, M. and Puteh, M., 2012. Blended learning or e-learning? International Magazine on Advances in Computer Science and Telecommunications, 3 (1), pp. 103-110.

Tsai. 2017. A blended learning lesson design for an EPUB3 e-book-based course. World Transactions on Engineering and Technology Education 15(2), pp. 94-101

Tsai, M. J. 2009. The model of strategic e-learning: understanding and evaluating student e-learning from metacognitive perspective. Educational Technology \& Society, 12(1), pp. 34-48.

Wan, Z., Compeau, D., and Haggerty, N. 2012. The effects of self-regulated learning processes on e-learning outcomes in organizational settings. Journal of Management Information Systems, 29, pp. 307-340.

Williams, G. 2011. EPUB: primer, preview, and prognostications. Collection Management, 36(3), pp. 182-191.

Wu, J.H., Tennyson, R.D., and Hsia, T.L., 2010. A study of student satisfaction in a blended e-learning system environment. Computers and Education, 55(1), pp.155-164. 